\title{
PROJETO DE EXTENSÃO BIOMEDICINA NA ESCOLA: UM RELATO DE EXPERIÊNCIA
}

\author{
BIOMEDICINE EXTENSION PROJECT IN SCHOOL: AN EXPERIENCE \\ REPORT
}

\section{Carla Danielle Dias Costa}

Docente da Faculdade Evangélica de Ceres, Goiás - GO, Brasil. carladaniellebm@gmail.com

\section{Larisse Silva Dalla Libera}

Docente da Faculdade Evangélica de Ceres, Goiás - GO, Brasil. larisse.dalla@ gmail.com

\section{Resumo}

A Biomedicina é um curso da área da saúde que teve seu surgimento no de 1966 e a partir da sua regulamentação em 1979, foram estabelecidos os campos de atuação que são atualizados constantemente. As Diretrizes Curriculares Nacionais dos Cursos de Graduação em Biomedicina estabelecem a relevância das atividades extensão no processo de formação do profissional Biomédico. O objetivo deste artigo é descrever a percepção docente em relação as atividades discentes realizadas no Projeto de extensão Biomedicina na Escola. O presente trabalho trata - se de um relato de experiência referente ao projeto Biomedicina na Escola, que foi desenvolvido durante os primeiros semestres letivos dos anos de 2018 e 2019 pelos alunos dos primeiros períodos do curso de Biomedicina de uma instituição de ensino superior privada da cidade de Ceres - GO. Ao longo do desenvolvimento do projeto foi possível identificar o envolvimento dos discentes do curso de Biomedicina na construção dos materiais a serem apresentados nas escolas. $\mathrm{O}$ fato de os discentes entrarem em contato com as escolas e desenvolverem suas atividades com os alunos, os tornam agentes ativos no processo de ensino aprendizagem. O projeto de extensão Biomedicina na Escola permitiu os discentes do primeiro período do curso de Biomedicina a experiência de entrar em contato com a comunidade, levando conhecimento científico de alta a qualidade a diversos alunos do ensino médio, assim como professores, coordenadores e diretores das escolas.

Palavras chaves: Biomédico, extensão, ensino médio, estudantes.

\begin{abstract}
Biomedicine is a health course that had its origin in 1966 and from its regulation in 1979 were established the fields of action that are constantly updated. The National Curriculum Guidelines for Undergraduate Biomedicine Courses establish the relevance of extension activities in the process of training the Biomedical professional. The purpose of this article is to describe the teaching perception regarding the student activities carried out in the Biomedicine Extension Project at School. This paper is an experience report related to the Biomedicine at School project, which was developed during the first semesters of 2018 and 2019 by students of the first periods of the Biomedicine course of a private higher education
\end{abstract}


institution in the city. of Ceres - GO. Throughout the project development it was possible to identify the involvement of Biomedicine students in the construction of materials to be presented in schools. The fact that students come into contact with schools and develop their activities with students makes them active agents in the teaching-learning process. The Biomedicine Extension Project at School allowed students in the first period of the Biomedicine course to experience contact with the community, bringing high quality scientific knowledge to various high school students, as well as teachers, coordinators and school principals.

Keywords: Biomedical, extension, high school, students.

Endereço para correspondência: Av. Brasil, s/n, Qd 13, Morada Verde, Ceres-Goiás,

Brasil. CEP: 76300-000. Fone: (62) 3323-1040.

E-mail: carladaniellebm@gmail.com

\section{Introdução}

O curso de Biomedicina foi implementado no Brasil pela primeira vez no ano de 1966 (CFBM, 2009). A lei 6.684 de 03 de Setembro de 1979 regulamentou a profissão, juntamente com o Decreto no 88.439 de 28/06/83, os quais delimitaram algumas das áreas de atuação do profissional Biomédico (BRASIL, 1979; BRASIL, 1983). Atualmente a profissão tem uma ampla aérea de atuação e é muito importante na melhoria da saúde pública do Brasil (CAMPOS, 2014).

A Biomedicina é enquadrada como sendo um curso da área da saúde, juntamente com outras 13 profissões, sendo elas: Ciências biológicas; Enfermagem; Educação Física; Farmácia; Fisioterapia; Fonoaudiologia; Medicina; Medicina Veterinária; Nutrição; Odontologia; Psicologia; Serviço Social; Terapia Ocupacional (BRASIL, 1998). O Biomédico é um profissional que têm competências e habilidades para atuarem em todos os níveis de atenção à saúde devido sua formação generalista, humanista, crítica e reflexiva, sempre amparado nos princípios intelectuais e da ciência (CFBM, 2009).

As Diretrizes Curriculares Nacionais (DCN) dos Cursos de Graduação em Biomedicina, definiram os princípios, fundamentos, condições e procedimentos essenciais para a formação de Biomédicos estabelecidos pela Câmara de Educação Superior (CES) do Conselho Nacional de Educação (CNE) do Ministério da Educação (MEC). No artigo $14^{\circ}$ deste documento é instaurado que a estrutura do curso de graduação em Biomedicina deverá assegurar a interlocução entre o ensino, pesquisa e extensão/assistência, proporcionando um 
ensino crítico, reflexivo e criativo, que estimule a realização de experimentos e/ou de projetos de pesquisa; de modo que é imprescindível o compartilhamento destes conhecimentos produzidos ao longo do da formação profissional com a comunidade (BRASIL, 2003).

As atividades realizadas através da extensão universitária são importantes possibilidades para a formação completa dos estudantes, por associar os conteúdos teóricos e práticos, visando atender demais da comunidade. É no desenvolvimento destas ações que é possível a troca de conhecimentos e informações, sendo possível a socialização e construção de novos saberes (MANCHUR, SURIANI, CUNHA, 2013).

A realização de ações extensionistas pode se dar em diversos locais fechados como hospitais, escolas, farmácias, creches, unidades de saúde, abrigos, assim como em espaços abertos como praças, feiras, avenidas. A etapa fundamental para o desenvolvimento das atividades se dá no planejamento das ações por parte dos docentes, discentes, coordenadores das instituições participantes, assim como órgãos gestores dos respectivos espaços, visando garantir qualidade e satisfação entre os agentes envolvidos, universidade e comunidade (CAIXETA, FIRMO, 2017).

A elaboração e execução de atividades de extensão em todos os cursos de Biomedicina devem ser constantes. Nesta perspectiva, o objetivo deste trabalho foi descrever a percepção docente em relação as atividades discentes realizadas no Projeto de extensão Biomedicina na Escola.

\section{Metodologia}

O presente trabalho trata - se de um relato de experiência referente ao projeto Biomedicina na Escola, que foi desenvolvido durante os primeiros semestres letivos dos anos de 2018 e 2019. A ação é referente a uma atividade de extensão realizada por alunos do curso de Biomedicina de uma instituição privada da cidade de Ceres - Goiás, coordenada pela docente da disciplina de Introdução a Biomedicina e desenvolvida pelos discentes do primeiro período do curso. Tal projeto visa levar informações sobre a Biomedicina e as áreas de atuação do Biomédico a estudantes da etapa final do ensino médio - $2^{\circ}$ e $3^{\circ}$ ano.

\section{Aproximação com a ação da Biomedicina na Escola}

O presente projeto foi idealizado a partir da apresentação de um trabalho de um grupo de discentes do segundo período do curso de Biomedicina, na disciplina de Fisiologia, no evento II Jornada de Biomedicina em Novembro de 2017. Ao longo da apresentação os 
estudantes relataram que os integrantes do grupo desenvolveram materiais sobre o tema da disciplina e fizeram a exposição destes materiais em uma sala de $3^{\circ}$ ano de uma escola de ensino médio da cidade de Ceres - Goiás. Ao final da exposição foram feitos alguns questionamentos aos estudantes, a fim de avaliar o conhecimento sobre o tema abordado, sobre a iniciativa do grupo e também foram levantadas algumas dúvidas por partes dos estudantes.

\section{Estruturação do Projeto Biomedicina na Escola}

Durante a semana de planejamento pedagógico do semestre 2018-1, a docente responsável pela disciplina de Introdução a Biomedicina (do primeiro período do curso de Biomedicina), inseriu dentro do Plano de ensino e Aprendizagem o planejamento e execução desta atividade de extensão durante o período letivo da disciplina, visando dar continuidade a atividade que foi realizada no ano anterior.

Os discentes elaboraram um projeto contendo detalhadamente as etapas a serem executadas nesta atividade, informando a escola na qual seria realizada a intervenção, as duas áreas de atuação do Biomédico que seriam trabalhadas com os alunos, quais os recursos seriam utilizados, como maquetes, apresentações em power point, data show, questionários, dinâmicas e afins.

Todas as etapas de estruturação do projeto foram supervisionadas pelas docentes da disciplina de Introdução a Biomedicina e Metodologia Científica. A escolha das escolas e a solicitação de autorização da direção das instituições foram feitas pelo contato dos alunos do curso de Biomedicina. Em situações nas quais foram solicitados ofício institucional, para formalizar e garantir a veracidade do projeto, a coordenação do curso prontamente os disponibilizou.

\section{Elaboração dos Materiais a serem apresentados nas escolas}

No início dos semestres dos anos de 2018 e 2019 os discentes adquiriam conhecimentos sobre a Biomedicina, informações quanto surgimento do curso, objetivos, quais as disciplinas básicas e específicas, assim como as áreas de atuação e habilitações do Biomédico. Ao longo do período letivo os mesmos foram informados sobre os objetivos do projeto e também sobre a elaboração e construção dos materiais a serem apresentados para as turmas de $2^{\circ}$ e $3^{\circ}$ ano do ensino médio. 
Foram desenvolvidos ao longo das aulas cartazes, maquetes (Figura 1), protótipos e apresentações em power point sobre as diversas áreas de habilitação do profissional Biomédico, tais como genética, reprodução humana e assistida, toxicologia, banco de sangue, perfusão extracorpórea, virologia, estética, acupuntura, perícia criminal, hematologia, análises clínicas, citopatologia, microbiologia e outras. Todo material produzido foi avaliado e corrigido pela docente da disciplina de Introdução a Biomedicina.

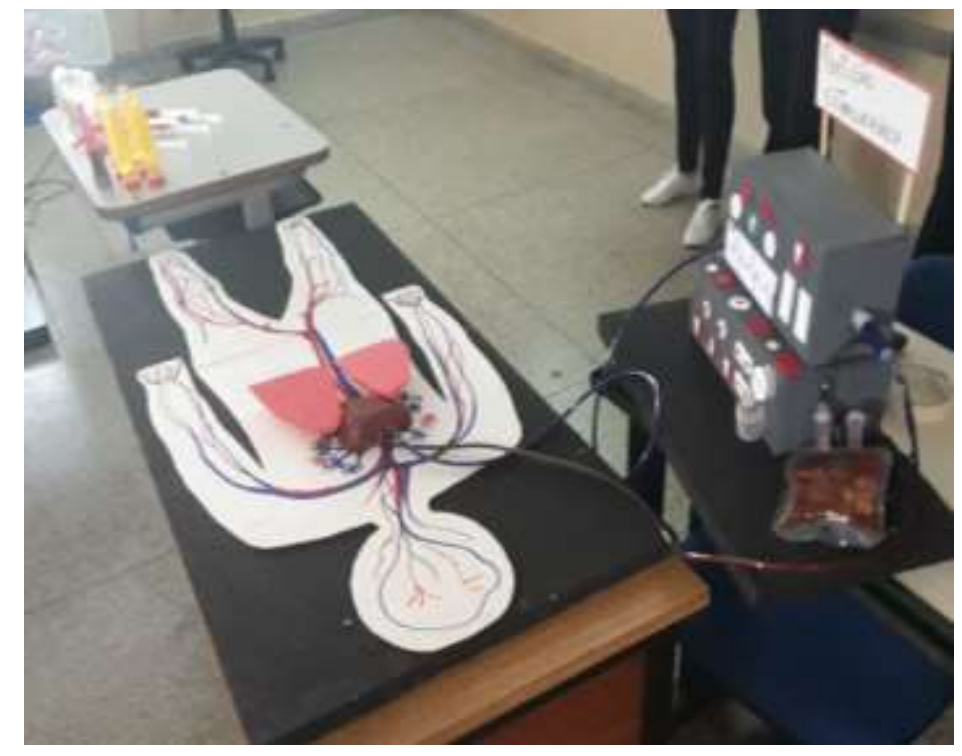

Figura 1. Maquete desenvolvida para o Projeto de Extensão Biomedicina na escola sobre a habilitação do Biomédico em Perfusão Extracorpórea.

\section{Execução do Projeto de Extensão Biomedicina na Escola}

As atividades de extensão do projeto Biomedicina na Escola foram realizadas nos meses de Maio e Junho dos anos de 2018 e 2019. Foram selecionadas pelos discentes escolas públicas e privadas da região do Vale do São Patrício como: Ceres, Rialma, Rubiataba, Jaraguá, Crixás de Goiás, Itapuranga, Santa Isabel, Uruana.

Nos dias estabelecidos os estudantes do curso de Biomedicina se apresentaram nas referidas escolas, portando os materiais elaborados e foram direcionados para as salas em que realizariam as atividades. O número de estudantes nas salas variou entre 15 a 45 indivíduos. As intervenções tiveram duração de cerca de 60 minutos e foram desenvolvidas nos períodos matutino, vespertino e noturno.

\section{Resultados e Discussão}

As atividades de extensão desenvolvidas pelas instituições de ensino superior baseiam - se na aproximação da comunidade com os produtos que são desenvolvidos nas pesquisas e 
no ensino, de maneira que é feita realizada uma troca de conhecimentos entre as partes, visando levar informações pertinentes aquela determinada comunidade, permitindo assim que as demandas sejam cumpridas e que visem minimizar as desigualdades sociais (JAZINE, 2004)

Durante o desenvolvimento do projeto foi possível identificar o envolvimento dos discentes do curso de Biomedicina na construção dos materiais a serem apresentados nas escolas. No decorrer das aulas os grupos se mostraram apreensivos com a proposta da atividade, pois não tinham conhecimento sobre quais estratégias seriam melhor abordadas para a prática da atividade.

No decorrer do semestre letivo, os mesmos foram adquirindo informações sobre o curso e sobre a disciplina, de modo que conheceram a trajetória da Biomedicina no país, assim como a finalidade do surgimento do curso no ano de 1966 e também sobre as 37 áreas de habilitações do profissional Biomédico. A partir da concretização destes conteúdos, os discentes conseguiam propor dinâmicas e atividades lúdicas que abordassem sobre os temas que seriam trabalhados nas escolas.

As práticas de educação social no Brasil não seguem uma metodologia exclusiva, elas ultrapassam o ensino tradicional, no qual os docentes representam os detentores do conhecimento, apenas repassando de maneira passiva as informações. Ao longo das práticas extensionistas são propostas didáticas diferenciadas e contextualizadas na realidade daquela determinada comunidade (RIBEIRO, 2006). Com base nisso e visando a interação dos alunos do ensino médio, várias metodologias foram utilizadas, como jogo de perguntas e repostas, gincanas, caça ao tesouro.

Durante a fase de execução das atividades do projeto de extensão, os discentes foram totalmente autônomos no processo de busca e escolha da escola em que se realizariam as ações, assumindo a responsabilidade de explicar os objetivos do projeto e solicitar ao grupo gestor da unidade a autorização para o desenvolvimento das mesmas. Diversos grupos optaram por fazer as devidas solicitações nas escolas em que já haviam estudado anteriormente, justamente por terem familiaridade com o ambiente de ensino, com os professores, coordenadores e diretores destas instituições, de modo que se sentiriam mais confortáveis para a execução do projeto.

A partir do momento em que os ambientes educacionais apresentam um clima afetivo em suas instalações, o aluno desenvolve um sentimento de pertencimento, de modo que se 
sinta integrado, acolhido e que terá suas dúvidas e seus pedidos de ajuda atendidos. Tal pensamento possibilita que o aluno se sinta motivado a aprender e também a ensinar (BORUCHOVITCH, 2009). Vale ressaltar que os mesmos também se sentiram valorizados e importantes, pelo fato de estarem retornando à escola que estudaram por determinado período, reencontrado amigos, professores, funcionários, porém agora assumindo o papel de multiplicadores do conhecimento.

A ação dos discentes entrarem em contato com as escolas e desenvolverem suas atividades com os alunos, os tornam agente ativo no processo de ensino aprendizagem, de forma que os mesmos desempenharam habilidades e competências gerais inerentes do profissional biomédico, no qual contempla as Diretrizes Curricular de Biomedicina, como comunicação, liderança, atenção a saúde e tomada de decisão (BRASIL, 2003).

A extensão universitária é capaz de produzir conhecimento a partir da experiência com os participantes da comunidade, garantindo um aprendizado completo. Ela proporciona a oportunidade de vivenciar outra realidade e conhecer os valores de uma sociedade, além dos conteúdos discutidos e trabalhados nas salas de aula das instituições de ensino superior (CASTRO, 2004).

\section{Conclusão}

O projeto de extensão Biomedicina na Escola permitiu os discentes do primeiro período do curso de Biomedicina a experiência de entrar em contato com a comunidade, levando conhecimento científico de alta a qualidade a diversos alunos do ensino médio, assim como professores, coordenadores e diretores das escolas.

Foi possível identificar que na maioria das instituições estas atividades não acontecem regularmente e que ações como tais proporcionam aos alunos do ensino médio conhecimento sobre as profissões muitas vezes desconhecidas, como é o caso da Biomedicina e em contrapartida colabora com as escolas em prepara-los para ingressarem em uma instituição de ensino superior.

Através da elaboração dos materiais pelos grupos, a execução das atividades propostas e o feedback positivo dos gestores das escolas sobre a importância e a relevância das atividades realizadas, foi possível perceber que os discentes do curso de Biomedicina se sentiram mais seguros em relação a escolha do curso e também mais capazes e confiantes no enfrentamento de desafios que serão propostos ao longo do curso. 


\section{Agradecimentos}

Diretores, Alunos, Professores e Coordenadores das Escolas Participantes. Coordenação do Curso de Biomedicina.

\section{Referências}

BORUCHOVITCH, E. A motivação do aluno (4. ${ }^{a}$ ed.). Rio de Janeiro: Editora Vozes (2009).

BRASIL. Conselho Nacional de Educação. Resolução CNE/CES 2, 18 de fevereiro de 2003. Diário Oficial da União de 20 de fevereiro de 2003, Brasília, 2003.

BRASIL. Decreto n⿳ 88.439, de 28 de Junho de 1983. Dispõe sobre a regulamentação do exercício da profissão de Biomédico de acordo com a Lei $\mathrm{n}^{\circ}$ 6.684, de 03 de setembro de 1979 e de conformidade com a alteração estabelecida pela Lei $n^{\circ} 7.017$, de 30 de agosto de 1982. Brasília, 1983.

BRASIL. Lei no 6.684, de 3 de setembro de 1979. Regulamenta as profissões de Biólogo e de Biomédico, cria o Conselho Federal e os Conselhos Regionais de Biologia e Biomedicina, e dá outras providências. Brasília, 1979.

BRASIL. Ministério da Saúde. Conselho Nacional de Saúde. Resolução no 287, de 8 de outubro de 1998. Estabelece categorias profissionais de saúde de nível superior para fins de atuação do Conselho. Diário Oficial da União de 07 de maio de 1999, Brasília, 1998.

CAMPOS, D. Manual do biomédico: história, atuação, importância para a saúde, para educação, e para a sociedade brasileira. 2014.

CASTRO, LM. CERQUEIRA. A Universidade, a extensão universitária e a produção de conhecimentos emancipadores. In: $27^{a}$ Reunião Anual da ANPED - Sociedade, Democracia e Educação: Qual Universidade? Caxambu. 2004.

CFBM. Biomedicina: Um painel sobre o profissional e a profissão. Conselho Federal e Conselho Regional de Biomedicina. 2009. 
JEZINE, E. As práticas Curriculares e a Extensão Universitária. Anais do $2^{\circ}$ Congresso Brasileiro de Extensão Universitária. Belo Horizonte. 2004.

MANCHUR, J; SURIANI, ALA; CUNHA, MC. A contribuição de projetos de extensão na formação profissional de graduandos de licenciaturas. Revista Conexão UEPG. volume 9 número2 - jul./dez. 2013.

RIBEIRO, M. Exclusão e educação social: conceito em superfície e fundo. Rev. Educ. Soc., vol. 27, n. 94, p.155-178, jan./abr. 2006. 